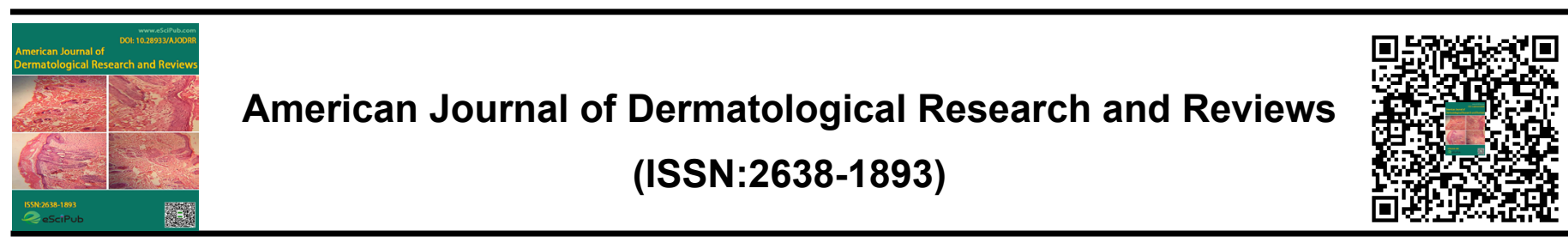

\title{
Vitiligo Treated by Soaking in an Earth Pond Containing KELEA Activated Water
}

\author{
W. John Martin ${ }^{1^{*}}$ and Shera Sandwell ${ }^{1}$ \\ ${ }^{1}$ Institute of Progressive Medicine, 1634 Spruce Street, South Pasadena CA 91030 USA.
}

\begin{abstract}
Vitiligo completely regressed in two patients who spent several hours for each of three consecutive days in a pond that contains water with a heightened quantity of a non-thermal activity attributed to a natural force called KELEA (Kinetic Energy Limiting Electrostatic Attraction). KELEA is further defined as the source of cellular energy, which comprises the alternative cellular energy (ACE) pathway. The ACE pathway differs from the cellular energy obtained from food metabolism. It is expressed as an added dynamic (kinetic) quality of the body's fluids. The body utilizes the ACE pathway in both chemical and electrical cellular reactions, including the recovery and regenerative processes following cellular damage. The ACE pathway supports the higher levels of brain functioning including the likelihood of improving upon the presumed KELEA receiving capacity of the brain. The ACE pathway can also limit the triggering and maintenance of

the inflammatory response. Each of these activities is presumably involved in the clinical regression of the vitiligo in the two patients. Enhancing the ACE pathway may provide an effective therapeutic approach for many patients with vitiligo.
\end{abstract} ${ }^{*}$ Correspondence to Author: W. John Martin Institute of Progressive Medicine, 1634 Spruce Street, South Pasadena CA 91030 USA.

How to cite this article:

W. John Martin, Shera Sandwell. Vitiligo Treated by Soaking in an Earth Pond Containing KELEA Activted Water.American Journal of Dermatological Research and Reviews, $2020 ; 3: 32$

Keywords: Vitiligo; Stealth adapted viruses; Alternative cellular eScîPub energy; ACE pathway; Kinetic energy limiting electrostatic Website: https://escipub.com/ attraction 


\section{Introduction}

Vitiligo is a disease characterized by the loss of melanin pigment in one or more circumscribed areas of the skin ${ }^{[1]}$. The term is derived from the Latin word "vitellus" meaning veal, in reference to the paleness of the skin. Vitiligo is distinguished from the overall lack of skin pigmentation leading to albinism ${ }^{[2]}$. Vitiligo affects approximately $1 \%$ of the human population ${ }^{[3]}$. It can be localized to only a single small patch of skin or can be more widely distributed as multiple nonpigmented patches on the body. Vitiligo is particularly noticeable in those of African heritage and especially when it involves the face.

The term melanin is derived from the Greek word melanos, meaning dark. The basic lightabsorbing compounds, which comprise melanin are polymers of oxidized phenols, including quinones, with mineral binding capacities. The phenolic ring is generally derived from the amino acid tyrosine. The extent of polymerization and other structural changes result in a diverse array of compounds included within the term melanin [4]. Different types of melanins are distributed throughout evolution, including being present in some unicellular prokaryote and eukaryote organisms and in all fungi, plants and animals ${ }^{[5-8]}$. In humans, melanin is the principal component responsible for skin and hair pigmentation, with marked differences in its levels in different racial groups ${ }^{[9]}$. The skin melanin is synthesized in neural-derived cells called melanocytes. The produced melanin is further distributed to neighboring keratinocytes and to hair follicles. Melanin is also present in other body sites, including the eye, inner ear, meninges, and the substantia nigra in the brain ${ }^{[10-14]}$.

Vitiligo occurs because of the marked reduction of melanocytes in affected skin areas. There is also a failure of the remaining melanocytes to produce melanin ${ }^{[15]}$. Subtle degenerative changes can also be detected in some keratinocytes [16]. The loss of melanocytes is variously attributed to a primary immunological or autoimmune disease or, alternatively, to some other melanocyte destroying process, with a secondary immune (inflammatory) component [17-21].
The patchy nature of the illness is difficult to explain by a systemic immune disorder, suggesting that there must be localized factors leading to the primary degeneration of melanocytes. Still, certain pharmaceutical drugs can also induce localized vitiligo in susceptible individuals ${ }^{[22]}$. Melanin can both protect cells from reactive oxygen species (ROS) and can also be a source of these toxins, which if excessive can kill the cell. Consistent with an overproduction of ROS is evidence for the unfolded protein response (UPR) [23]. Virus infections can also induce the UPR [24] and are also considered to be a possible contributory factor to vitiligo, with emphasis being given to human herpesviruses ${ }^{[25]}$. There is an analogy with herpes zoster virus induced shingles, especially when the vitiligo is segmented and only affects a unilateral area of the skin corresponding to a particular nerve supply.

Vitiligo can be accompanied by major psychiatric symptoms, including depression, anxiety and low self-esteem [26, 27]. These are generally seen as secondary consequences of the stigma and unsightliness of the illness. It is likely, however, that emotional stress plays a major contributory role in the illness. Genetic factors have also be implicated in the disease [28].

Up to now, there has been no consistently successful method for treating vitiligo. Ultraviolet radiation is commonly used to induce melanin production with the optional addition of various photosensitizers, such as psoralens ${ }^{[29-31]}$. Several compounds can seemingly increase the production of tyrosine, including phenylalanine, its precursor amino acid ${ }^{[32]}$. Efforts to increase the activity of tyrosine and other Janus kinases (JAK) led to the unanticipated finding that JAK inhibitors were able to achieve partial re-pigmentation of vitiligo affected skin areas. In addition to their role in melanin production, JAX are involved in immune activation. JAK inhibitors are presumed, therefore, to act by reducing the immunological mediated destruction of melanocytes ${ }^{[33]}$. Grafting of normally pigmented skin into the affected areas has been tried with marginal success ${ }^{\text {[34- }}$ 35]. The many empirically-based approaches to 
treating vitiligo underscore their overall ineffectiveness ${ }^{[36]}$.

We wish to propose that vitiligo is likely caused by infection of the melanocytes with stealth adapted viruses and that recovery is achievable by enhancing the alternative cellular energy (ACE) pathway. Stealth adapted viruses differ from the viruses from which they are derived in that they do not evoke anti-virus inflammation [3739]. This is because the genes coding for the relatively few virus components that are normally targeted by the cellular immune system are either deleted or mutated. Infections with stealth adapted viruses can still, however, be suppressed through a non-immunological mechanism that relies on a source of cellular energy that is different from the cellular energy obtained from the metabolism of food. The ACE pathway is expressed as an added dynamic or kinetic property of the body's fluids. It is maintained by the continuing absorption into the body of an environmental force called KELEA, an abbreviation for Kinetic Energy Limiting Electrostatic Attraction. The fluctuating electrical activity of the brain is the likely major receiver of KELEA into the body [38]. This function is impaired in individuals with brain illnesses. KELEA can also be absorbed into water. KELEA activated water is naturally present in certain locations or can be manufactured by either the addition of KELEA attracting dipolar compounds, referred to as enerceuticals $^{\mathrm{TM}}$, or placed in an area with an elevated environmental level of KELEA [40-48].

A natural source of KELEA activated water was identified as coming from a deep (>800 feet) well in a ranch in San Marcos, CA. Some of the water was repeatedly applied to a somewhat barren, stone-laden hilltop within the ranch. The bucket on a frontend bulldozer broke while trying to move some of the embedded rock material, later identified as petrified ancient oak trees. This area was used to create a pond. Over the ensuring 12 years, the underlying solid material has been broken down into a granular, mud-like material. A lush growth of algae is on the surface of the pond. Fresh well water is periodically added to the pond. Rescued and abandoned horses brought onto the ranch were noted to commonly drink from the pond with obvious benefits to their health. This use was extended to the daily use by a very sick human, with major improvements in her health. There are now many additional examples of individuals recovering from chronic illnesses by either soaking in the pond or by directly consuming the well water. Examples of these favorable clinical outcomes will be described in further publications. This particular article is intended to indicate the remarkable benefits of soaking in the pond in the rapid disappearance of vitiligo.

\section{Clinical Descriptions}

A Hispanic woman was disfigured with vitiligo affecting the lower half of her lower lip. She also showed extensive areas of depigmentation on the back of her left hand. She was invited to spend time in the pond. It also only required spending a few hours each day for 3 days for both her lower lip and her hand to appear normal. Restoration of the color of her lower lip along with an overall improvement in her facial complexion resulted in her appearing to be far younger than it was at first believed. Indeed, the gentleman who had accompanied the woman to the ranch was initially believed to be her son. With the regained normal facial appearance, it was apparent that he was her husband.

In a second example, a middle-age African American woman was disfigured by vitiligo, which had extensively affected both cheeks on her face. It had been present for several years. She was encouraged by the results in the Hispanic lady to spend approximately three hours a day for three days with her legs in the water of the pond. During these periods, she was instructed to repeatedly apply the water and granular mud-like material to her cheeks. Even at the end of the first day, an increase in coloration in her cheeks was noted. It became more obvious after the second day. By the end of the third day, the normal level of facial pigmentation was restored. The personality of the woman also markedly improved from being somewhat irritable to being far more sociable. 
Both of the treated women were hugely impressed and joyful with the results. They were each invited to have repeat treatments should the vitiligo ever return. Neither of the women ever did!

\section{Discussion}

Although only two patients, the results are rather remarkable in the rapidity and completeness of recovery from vitiligo. The healing process is attributed to a combination of three factors. First, suppression of stealth virus infection if indeed this is the primary cause of the vitiligo. Second, an anti-inflammatory effect presumably evoked by the destruction and degeneration of the melanocytes. Third, the regeneration of new melanin-producing melanocytes. The anti-inflammatory effect of KELEA activated water is explained by added resilience and increased threshold needed to trigger the release and to respond to inflammatory cytokines. The regenerative effect of KELEA activated water are embodied in the term REACH, an abbreviation for Regenerative Energy Assisted Clinical Healing.

Although specifically describing the recovery from vitiligo, the thesis of this article has many broad potential applications. Melanin deficiency can affect many other processes in the body. Parkinson's disease is one example in which there is degeneration of melanin containing cells in the substantia nigra ${ }^{[49-51]}$. Individuals with Parkinsonism have benefited from spending time in the pond (unpublished). Melanin can also contribute to the inner ear and to the eyes. In a broader sense, vitiligo is generally grouped along with a wide range of autoimmune diseases. Combining anti-inflammatory and tissue regenerative effects of KELEA activated water can potentially lead to the recovery from many types of chronic illnesses.

The pond has the advantage of allowing for prolonged exposure to the KELEA activated water over several hours. The presence of the lush algae and degraded petrified, mud-like material adds to the ambiance of the experience. Neither of these factors can be as easily achieved using a skin spray or merely drinking the KELEA activated water. An additional option is to include
KELEA activated water in wearable waterceutical pouches ${ }^{\mathrm{TM}}$, which can be directly applied to the affected areas of the skin. These pouches are currently being used as a general means of boosting the level of overall wellness in patients with various chronic illnesses. In a limited and ongoing study, the pouches are expediting the post-exercise recovery of horses (unpublished).

Declarations: The authors report they have no conflicts on interests in reporting the results.

The reporting of the clinical observations was reviewed and approved by The Center for Complex Infectious Diseases (CCID) Institutional Review Board (IRB).

The use of KELEA activated water was determined by the IRB to be a benign energy-based medical device intervention, to which the participants had voluntarily consented.

The study was performed without costs to the participants.

The study was supported by MI Hope Inc., a non-profit public charity.

\section{References}

1. Bergqvist C, Ezzedine K (2020) Vitiligo: A review. Dermatology, 10: 1-22. doi:10.1159/0005 06103.

2. Marçon CR, Maia M (2019). Albinism: epidemiology, genetics, cutaneous characterization, psychosocial factors. Anais brasileiros de dermatologia, 94(5): 503-520.

https://doi.org/10.1016/j.abd.2019.09.023.

3. Krüger C, Schallreuter K U (2012). A review of the worldwide prevalence of vitiligo in children/adolescents and adults. International Journal of Dermatology, 51(10): 1206-1212. doi: 10.1111/j.1365-4632.2011.05377.x.

4. Solano F (2014) Melanins: Skin pigments and much more-Types, structural models, biological functions, and formation routes. New J Science Article ID 498276, doi.10.1155/2014/498 276.

5. Plonka PM, Grabacka M (2006) Melanin synthesis in microorganisms--biotechnological and medical aspects. Acta Biochim Pol. 53(3): 42943.

6. Vasileiou $T$, Summerer $L$ (2020) A biomimetic approach to shielding from ionizing radiation: The case of melanized fungi. PLOS ONE, 15(4): e0229921.

https://doi.org/10.1371/journal.pone.0229921 
7. Zou Y, Zhao Y (2015) Properties of melanin from black tea leaves. ScienceAsia, 41: 400404 doi: 10.2306/scienceasia1513-1874.2015. 41.400.

8. Riley PA (1997) Melanin. Int J Biochem Cell Biol. 29(11):1235-9.

9. Quevedo Jr WC, Fitzpatrick TB, Jimbow K (1985) Human skin color: origin, variation and significance. Journal of Human Evolution, 14(1): 43-56.

10. Hu DN, Simon JD, Sarna T (2008) Role of ocular melanin in ophthalmic physiology and pathology. Photochem Photobiol.84(3): 639-44. doi: 10.1111/j.1751-1097.2008.00316.x.

11. Goldgeie MH, Klein LE, Klein-Angerer S, et al. (1984) The distribution of melanocyte in the leptomeninges of the human brain. $J$ Invest Dermatol, 82: 235-238.

12. Zecca L, Tampellini D, Gerlach M, et al. (2001). Substantia nigra neuromelanin: structure, synthesis, and molecular behaviour. Molecular Pathology: MP 54(6): 414-418.

13. Gibb W R, Lees A J (1991). Anatomy, pigmentation, ventral and dorsal subpopulations of the substantia nigra, and differential cell death in Parkinson's disease. Journal of Neurology, Neurosurgery, and Psychiatry, 54(5): 388-396. https://doi.org/10.1136/jnnp.54.5.388

14. Rahimi H, Mozafari N, Bastaninejad S, et al. (2019). Hearing status in patients with vitiligo. Clinical, Cosmetic and Investigational Dermatology, 12: 445-450.

https://doi.org/10.2147/CCID.S201012

15. Tobin DJ, Swanson NN, Pittelkow MR, et al. (2000) Melanocytes are not absent in lesional skin of long duration vitiligo. J Pathol, 191: 407-16.

16. Moellmann G, Klein-Angerer S, Scollay DA, et al. (1982) Extracellular granular material and degeneration of keratinocytes in the normally pigmented epidermis of patients with vitiligo. $J$ Invest Dermatol, 79(5): 321-30.

17. Manga P, Elbuluk N, Orlow S J (2016). Recent advances in understanding vitiligo. F1000Research, 5, F1000 Faculty Rev: 2234 https://doi.org/10.12688/f1000research.8976.1

18. Sharquie KE, Mehenna SH, Naji AA, et al. (2004) Inflammatory changes in vitiligo: Stage I and II depigmentation. Am J Dermatopathol. 26(2): 108-12.

19. Wang Y, Li S, Li C (2019). Perspectives of new advances in the pathogenesis of vitiligo: From oxidative stress to autoimmunity. Medical Science Monitor: International Medical Journal of Experimental and Clinical Research, 25: 10171023. https://doi.org/10.12659/MSM.914898
20. Harris J E (2016). Cellular stress and innate inflammation in organ-specific autoimmunity: lessons learned from vitiligo. Immunological Reviews, 269(1): 11-25.

https://doi.org/10.1111/imr.12369

21. Ding GZ, Zhao WE, Li X, et al. (2015) A comparative study of mitochondrial ultrastructure in melanocytes from perilesional vitiligo skin and perilesional halo nevi skin. Arch Dermatol Res. 307(3): 281-9. doi: 10.1007/s00403-0151544-4.

22. Curzytek K, Pietowska J, Spiewak R (2007) Drug-induced vitiligo: A meta-analysis of reported cases. Allergy (Suppl 83: XXVI Congress of the European Academy of Allergology and Clinical Immunology) 62: 447.

23. Toosi S, Orlow S J, Manga P (2012). Vitiligoinducing phenols activate the unfolded protein response in melanocytes resulting in upregulation of IL6 and IL8. Journal of Investigative Dermatology, 132(11): 2601-2609. https://doi. org/10.1038/jid.2012.181.

24. Chan S W (2014). The unfolded protein response in virus infections. Frontiers in Microbiology, 5: 518.

https://doi.org/10.3389/fmicb.2014.00518

25. Dwivedi M, Laddha NC, Begum R (2018) Viral causes of vitiligo: A new perspective for vitiligo pathogenesis. Virology \& Immunology Journal 2(8): 000181.

26. Simons RE, Zevy DL, Jafferany M (2020) Psychodermatology of Vitiligo: Psychological impact and consequences. Dermatol Ther, e13418. doi: $10.1111 /$ dth. 13418 .

27. Grimes P E, Miller M M (2018). Vitiligo: Patient stories, self-esteem, and the psychological burden of disease. International Journal of Women's Dermatology, 4(1), 32-37.

https://doi.org/10.1016/j.ijwd.2017.11.005

28. Spritz R A, Andersen G H (2017). Genetics of vitiligo. Dermatologic Clinics, 35(2): 245-255. https://doi.org/10.1016/j.det.2016.11.013

29. Zubair R, Hamzavi IH (2020) Phototherapy for Vitiligo Dermatol Clin, 38(1): 55-62. doi: 10.1016/j.det.2019.08.005.

30. Bae J M, Jung H M, Hong B Y, et al. (2017). Phototherapy for Vitiligo: A Systematic Review and Meta-analysis. JAMA Dermatology, 153(7) : 666-674. https://doi.org/10.1001/jamadermatol.2017.0002

31. Westerhof W, Nieuweboer-Krobotova L (1997) Treatment of vitiligo with UV-B radiation vs topical psoralen plus UV-A. Arch Dermatol, 133(12):1525-1528.

32. Gianfaldoni S, Tchernev G, Lotti J, et al. (2018). Unconventional treatments for vitiligo: 
Are they (un) satisfactory? Macedonian Journal of Medical Sciences, 6(1): 170-175.

https://doi.org/10.3889/oamjms.2018.038

33. Phan K, Phan S, Shumack S, Gupta M (2020) Repigmentation in vitiligo using janus kinase (JAK) inhibitors with phototherapy: systematic review and Meta-analysis. J Dermatolog Treat. 1-5. doi:10.1080/09546634.2020.17356 15.

34. Zokaei S, Farhud DD, Keykhaei M, et al. (2019) Cultured epidermal melanocyte transplantation in vitiligo: a review article. Iran J Public Health, 3: 388-399.

35. Khunger N, Kathuria S D, Ramesh V (2009). Tissue grafts in vitiligo surgery - past, present, and future. Indian Journal of Dermatology, 54(2): 150-158.

https://doi.org/10.4103/0019-5154.53196

36. Frisoli ML, Essien K, Harris JE (2020) Vitiligo: Mechanisms of Pathogenesis and Treatment. Annu Rev Immunol. 38: 621-648. doi:10.1146/ annurev-immunol-100919-023531.

37. Martin WJ (2014) Stealth Adapted Viruses; Alternative Cellular Energy (ACE) \& KELEA Activated Water: A New Paradigm of Healthcare. Author House Bloomington IN p321

38. Martin WJ (2014) Stealth adaptation of viruses: Review and updated molecular analysis on a stealth adapted African green monkey simian cytomegalovirus (SCMV). J Hum Virol Retrovirol, 1(4): 00020. doi:10.15406/jhvrn.2014.01.0 0020

39. Martin WJ (2015) Stealth adapted viruses Possible drivers of major neuropsychiatric illnesses including Alzheimer's disease. J Neurol Stroke 2(3): 00057.

40. Martin WJ (2015) Is the brain an activator of the alternative cellular energy (ACE) pathway? International $J$ Complementary \& Alternative Medicine 1(1): 00002.

41. Martin WJ (2020) Enhancing the alternative cellu-lar energy (ACE) pathway with KELEA activated water as therapy for infectious diseases. Infect Disord Drug Targets. 20: Published online ahead of print, Feb. 10. doi:10.2174/18715265206620 0211115111

42. Martin WJ (2017) The many biological functions of the alternative cellular energy (ACE) pathway. International J Complementary \& Alternative Medicine 7(5): 00237.

43. Martin WJ (2017) Tissue regeneration without scarring achieved by enhancing the alternative cellular energy (ACE) pathway. J Cosmetics, Dermatological Sciences and Applications 7(1): 82-98.

44. Martin WJ (2016) The ACE pathway in comparison to the immune system in the defense against infectious diseases. J Human Virology \& Retrovirology. 3(5): 00124. doi: 10.15406/jh vrv.2016.04.00124

45. Martin WJ (2016) Deconstructing medicine: The alternative cellular energy pathway. British $J$ Medicine \& Medical Research, 11(8): 1-6.

46. Martin WJ (2016) Insufficiency of cellular energy (ICE). The basis for many illnesses potentially correctable using KELEA activated water. International J Complementary \& Alternative Medicine 4(1): 00106.

47. Martin WJ (2017) Hyper-excitability followed by functional quiescence in neuronal cells caused by insufficient cellular energy (ICE): Treatable by enhancing the alternative cellular energy (ACE) pathway. World $J$ Neuroscience 7(3): 257-266.

48. Martin WJ (2017) Insufficiency of cellular energy (ICE) may precede neurodegeneration in Alzheimer's disease and be treatable via the alternative cellular energy (ACE) pathway. $A d-$ vances in Alzheimer's Disease 6(1): 1-12.

49. Martin WJ (2017) Insufficiency of cellular energy (ICE) from the alternative cellular energy (ACE) pathway limiting the specialized functions of neuronal cells. Int $J$ Complement Alt Med., 4: 00112.

50. Brenner S (2014) Parkinson's disease may be due to failure of melanin in the Substantia Nigra to produce molecular hydrogen from dissociation of water, to protect the brain from oxidative stress. Med Hypotheses. 82(4): 503. doi:10.10 16/j.mehy.2014.01.013.

51. Enochs WS, Sarna T, Zecca L, et al. (1994) The roles of neuromelanin, binding of metal ions, and oxidative cytotoxicity in the pathogenesis of Parkinson's disease: a hypothesis. $J$ Neural Transm Park Dis Dement Sect. 7(2): 83-100.

52. Youdim MB, Ben-Shachar D, Riederer $P$ (1994)The enigma of neuromelanin in Parkinson's disease substantia nigra. I Neural Transm Suppl. 43:113-22. 